Article

\title{
Validity and Reproducibility of Various Linear Sweep Voltammetry Tests of Anode and Cathode Electrodes in Microbial Electrolysis Cells
}

\author{
Hyungwon Chai, Bonyoung Koo, Sunghoon Son, Sokhee P. Jung * \\ Department of Environment and Energy Engineering, Chonnam National University, Gwangju 61186, \\ Republic of Korea; chaiwon92@gmail.com \\ * Correspondence: sokheejung@gmail.com; Tel.: +82-62-530-1857
}

\begin{abstract}
Electrode is a key component in a microbial electrolysis cell (MEC) and it needs significant improvement for practical implementation of MEC. For effective development of electrode technology, accurate and reproducible analytical methods are very important. Linear sweep voltammetry (LSV) is an essential analytical method for evaluating electrode performance; however, it has not been firmly established yet in the MEC field. In this study, biological brush (BB), abiotic brush (AB), Pt wire (PtW), stainless steel wire (SSW) and mesh (SSM)) were tested to explore the most suitable counter electrode in different medium conditions. Coefficient of variation (CV) for Imax of LSV were comparatively analyzed. In BB-anode LSV, SSW (0.48\%) and SSM (2.17\%) showed higher reproducibility as a counter electrode. In SSM-cathode LSV, BB (1.76\%) and PtW $(2.01 \%)$ produced more reproducible results. In the Ni-AC-SSM-cathode LSV, PtW (3.54\%) and BB $(8.81 \%)$ produced more reproducible result. It shows electrode used in the operation is an appropriate counter electrode in the acetate-added condition. However, in the absence of acetate, $\mathrm{PtW}(1.24 \%)$ and BB $(1.71 \%)$ produced more reproducible results in SSM cathode and PtW $(0.61 \%)$ and SSW $(1.21 \%)$ did in the Ni-AC-SSM-cathode, showing PtW is an appropriate counter electrode. These results also shows that $\mathrm{PtW}$ is an appropriate counter electrode in cathode LSV.
\end{abstract}

Keywords: Microbial electrolysis cells; Linear sweep voltammetry; Counter electrode; Coefficient of variation; Reproducibility 

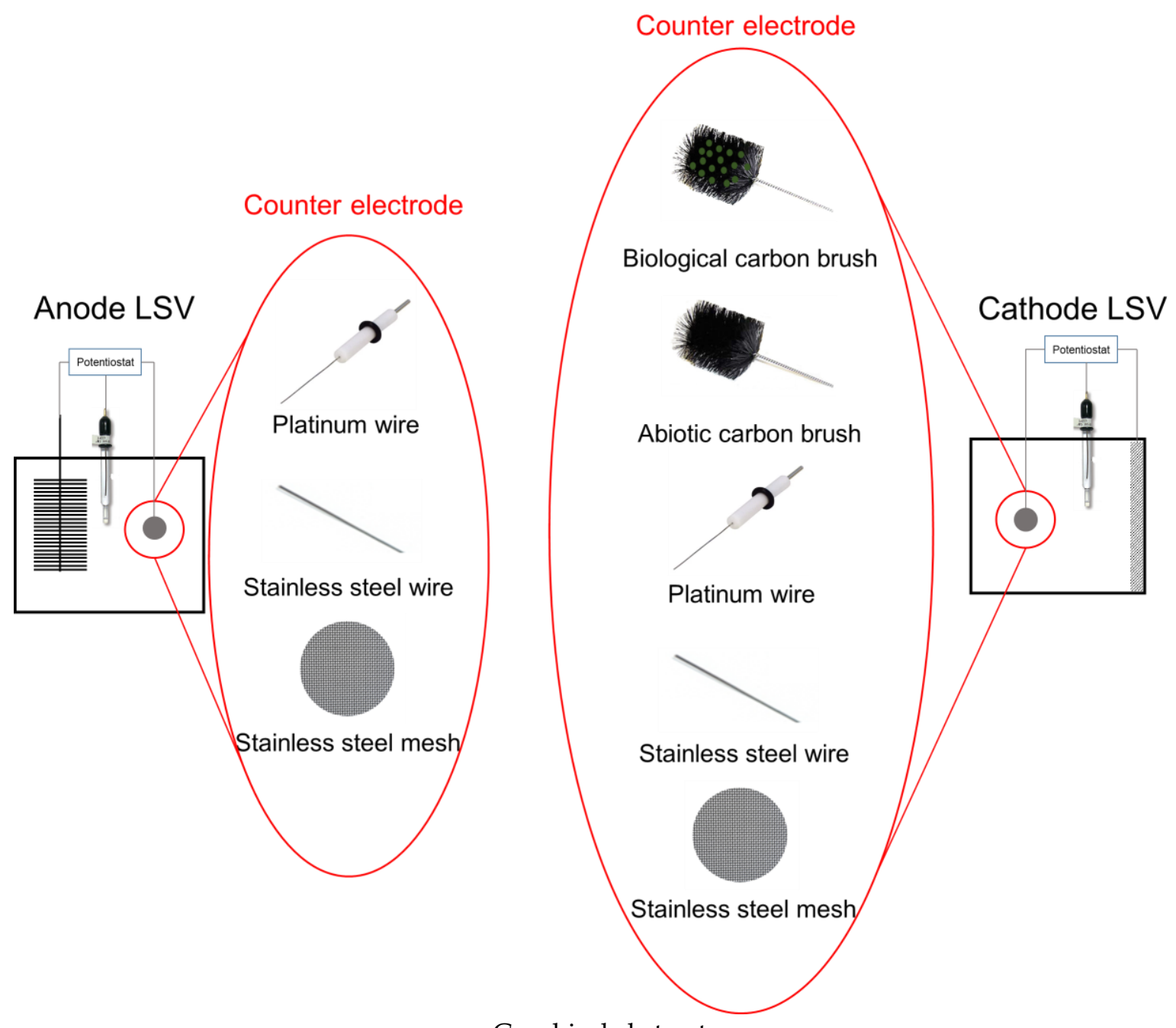

Graphical abstract

\section{Introduction}

Wastewater treatment is an energy-demanding process. Removal of organic matter, the main hazards of wastewater, is necessary to protect the water environment [1]. According to the EPA (United States Environmental Protection Agency), the annual amount of wastewater treated by wastewater treatment facilities is about 46.9 billion tons. Organic wastewater treatment consumes 15 GW, which is $3 \%$ of the total electricity production in the United States, and other developed countries show similar aspects [2]. Therefore, about $0.31 \mathrm{~W}$ of energy is consumed per ton of wastewater. The microbial electrochemical system (MES) is a potential energy-positive wastewater treatment systems that recover renewable energy or useful resources from wastewater [3-6].

Electrode is one of the most important parts in MES technology because most biotic or abiotic electrochemical reactions occur in anode and cathode electrodes. In MES experiments, electrode performance can be evaluated by using linear sweep voltammetry (LSV), cyclic voltammetry (CV), and electrochemical impedance spectroscopy (EIS). Among them, LSV is very easy to perform and produces reliable data, so that it is commonly performed in many areas such as microbial electrochemical systems (MES) [7-14], fuel cells [15,16], hydrogen generation technologies [17,18].

In general, electrochemical test is the analysis of chemical response when an electrical stimulus is applied to the system. In the LSV test, electrical stimulus is a change of potential, and chemical response is converted by the current signal. In the LSV test, to change the potential of electrode in a solution, two electrodes (working electrode and reference electrode) must be need to measure the potential. Current at a working electrode is measured while the potential between the working electrode and a reference electrode is swept linearly in time [19]. At this time, the potential (E) of the working electrode can be calculated as Eap minus $\mathrm{R}_{\mathrm{s}}[20]$. 
Eap is an applied voltage between working and reference electrode, $\mathrm{i}$ is a current of working electrode, $R s$ is a solution resistance. When the $\mathrm{iR}_{s}$ is less than $1 \mathrm{mV}$, it can be measured using a twoelectrode cell. Therefore, in case of measuring in the two-electrode cell, solution resistance and current of working electrode should be low. However, if solution resistance or current is high, it should use the three-electrode cell for minimizing the error by iRs. Electrode LSV tests in MES are mainly performed by using the three-electrode cell $[7,8,21]$, consist of a working electrode, reference electrode, and counter electrode. Counter electrode is that occurring a process opposite from the working electrode, it is not monitored. Various counter electrodes (platinum [8,22-24], dimensionally stable anode $[25,26]$ ) are used in MES, but no research has been conducted on the effect of counter electrode on LSV data validity and reproducibility.

Therefore, the aim of the present study is to evaluate the reproducibility according to the counter electrode in the anode and cathode LSV test in microbial electrolysis cell (MEC). In order to compare the reproducibility, counter electrodes used in this study are Pt wire, stainless steel wire and mesh in the anode LSV test. In the cathode LSV tests, biological brush, abiotic carbon brush, Pt wire, stainless steel wire and mesh were used as counter electrodes. Then, the reproducibility of cathode LSV test with different electrode performance and different experimental conditions was evaluated and compared. This study presents data that can be used to set the counter electrode according to the electrode LSV test conditions.

\section{Materials and Methods}

\subsection{Electrode fabrication}

In this study, two kinds of cathodes were fabricated to compare cathodes with different performance. Stainless steel mesh (SSM) cathode (surface area $7 \mathrm{~cm}^{2}$, \# 60, SUS 304) was used after treating it with a flame oxidation [27]. Activated carbon cathode with nickel powder (Ni-AC-SSM cathode) was fabricated for cathode LSV test [28], which has high catalytic activity for hydrogen evolution reactions (HER). Ni-AC-SSM cathode was made using $96.8 \mathrm{mg}\left(8.8 \mathrm{mg} / \mathrm{cm}^{2}\right)$ of Ni powder and $300 \mathrm{mg}\left(26.5 \mathrm{mg} / \mathrm{cm}^{2}\right)$ of AC powder, and $1 \mathrm{~mL}$ of PVDF [8]. A carbon brush anode was used as an anode electrode. Carbon fibers were twisted with two titanium rods (length $70 \mathrm{~mm}, 17$ gauge; grade 2, Seoul Titanium) [10], it was treated at $450{ }^{\circ} \mathrm{C}$ for 30 minutes in the furnace (FX/FHX, DAIHAN Scientific, South Korea) before inoculation [29].

\subsection{MEC configuration and operation}

Single chamber MEC reactor was fabricated with polycarbonate, having $28 \mathrm{~mL}$ cylindrical bed volume of $4 \mathrm{~cm}$ length and $3 \mathrm{~cm}$ diameter as described in the previous study [13].

Anode and cathode were horizontally faced to each other and spaced about $15 \mathrm{~mm}$ to prevent short circuits. The brush anode was inoculated from domestic wastewater (Gwangju Wastewater Treatment Plant) with effluents of primary sedimentation $(22.4 \mathrm{~mL})$ and the activated sludge $(5.6 \mathrm{~mL})$ in MFC mode with the $1000 \Omega$ external resistance. When the current of MFC was produced stably, the experiment was performed by switching to MEC mode. MEC was operated in $100 \mathrm{mM}$ carbonate buffer solution (CBS) in a fed batch mode with $10 \Omega$ external resistance at $30^{\circ} \mathrm{C}$. The CBS contained $\mathrm{NaH}_{2} \mathrm{PO}_{4} 0.026 \mathrm{~g} / \mathrm{L}, \mathrm{Na}_{2} \mathrm{HPO}_{4} 0.05 \mathrm{~g} / \mathrm{L}, \mathrm{NH}_{4} \mathrm{Cl} 0.31 \mathrm{~g} / \mathrm{L}, \mathrm{KCl} 0.13 \mathrm{~g} / \mathrm{L}, \mathrm{NaHCO}_{3} 8.4 \mathrm{~g} / \mathrm{L}$, trace minerals $1 \mathrm{ml} / \mathrm{L}$, vitamins $1 \mathrm{ml} / \mathrm{L}$ and sodium acetate $20 \mathrm{mM}$ as a substrate [12].

\subsection{Electrochemical test}

Linear sweep voltammetry (LSV) was performed using different counter electrodes to compare the electrochemical test reproducibility of anode and cathode performance. Open-circuit voltage (OCV) time of all anode LSV test was 90 minutes, LSV tests were measured using a potentiostat (SP1, 
WonATecH, South Korea). Platinum wire (PtW, length $5 \mathrm{~cm}$, diameter $0.5 \mathrm{~mm})$, stainless steel wire (SSW, length $5 \mathrm{~cm}$, diameter $0.5 \mathrm{~mm}$ ) and stainless steel mesh (SSM, surface area $7 \mathrm{~cm}^{2}$ ) were used as counter electrode for anode LSV tests. The scan rate of $1.0 \mathrm{mV} / \mathrm{s}$ was applied to anode over the potential range from open circuit potential (OCP) to $-0.2 \mathrm{~V} \mathrm{[14].}$

Biological brush (BB, length $25 \mathrm{~mm}$, diameter $25 \mathrm{~mm}$, inoculated), abiotic carbon brush (AB, length $25 \mathrm{~mm}$, diameter $25 \mathrm{~mm}$ ), PtW, SSW and SSM were used as counter electrode for cathode LSV tests. Cathode LSV tests were conducted in two experiments to compare reproducibility with only CBS ( $\mathrm{pH} 8.33$, conductivity $8.42 \mathrm{mS} / \mathrm{cm}$ ) and CBS with sodium acetate ( $\mathrm{pH} 8.31$, conductivity 9.75 $\mathrm{mS} / \mathrm{cm}$ ) as the electrolyte. The $\mathrm{pH}$ and conductivity were measured using a $\mathrm{pH} /$ conductivity meter (S213, METTLER TOLEDO, USA). The scan rate of $1.0 \mathrm{mV} / \mathrm{s}$ was applied to cathode over the potential range from $-0.3 \mathrm{~V}$ to $-1.2 \mathrm{~V}$. For all LSV tests, $\mathrm{Ag} / \mathrm{AgCl}$ reference electrode (RE-1B, ALS, Japan; -0.209 $\mathrm{V}$ vs. SHE) was inserted in the medium through a rubber gasket and located in the middle of MEC. LSV tests were performed in duplicate to reduce experimental error.

\subsection{Statistics}

In order to evaluate the reproducibility of the LSV test results, the average values and standard deviations of duplicate experiments were calculated. The standard deviation represents an absolute degree of value difference. So, a larger average of the values, higher standard deviation. However, the standard deviation is not suitable for comparison of samples with different average values. Therefore, the coefficient of variation $(\mathrm{CV})$ is useful for adjusting the standard deviation that varies due to differences in average values.

The coefficient of variation was calculated as,

$$
C V=\frac{\sigma}{\bar{x}} \times 100(\%)
$$

, where $\sigma$ is the standard deviation and $\bar{x}$ is the average value. The relatively small standard deviation compared to the average means that the degree of dispersion is low, and thus, it can be proved that the reproducibility of experiments is high. 


\section{Results}

\subsection{Anode linear sweep voltammetry test}

In order to compare the reproducibility of anode (biological brush) LSV tests, PtW, SSW and SSM were used as counter electrodes (Figure 1, S1).

Maximum current value of $\mathrm{PtW}$ using $\mathrm{Pt}$ wire as the counter electrode was $11.05 \pm 0.24 \mathrm{~mA}$. Maximum current values of SSW and SSM using stainless steel wire and mesh as the counter electrode were $11.11 \pm 0.05 \mathrm{~mA}$ and $12.59 \pm 0.06 \mathrm{~mA}$, respectively (Table 1). Coefficient of variation (CV) of maximum currents was the lowest in SSW $(0.45 \%)$, followed by SSM $(0.48 \%)$ and PtW $(2.17 \%)$ (Figure 2). SSW and SSM had 79.2\% and 77.8\% lower CV than PtW. The reproducibility of anode LSV test was high in SSW and SSM.

\section{(Figure 1, Figure 2)}

\subsection{Stainless steel mesh (SSM) cathode linear sweep voltammetry test}

In order to compare the reproducibility of cathode LSV tests, BB, AB, PtW, SSW and SSM were used as counter electrodes. Cathode LSV test is practically performed without acetate filled, unlike the anode LSV. However, the reproducibility of the LSV tests with acetate filled was evaluated in this study (Figure 3, S2).

Maximum current values of BB and AB in cathode LSV test with acetate filled were $-8.79 \pm 0.15$ and $-7.12 \pm 0.25 \mathrm{~mA}$, respectively. Maximum current value of PtW using Pt wire as the counter electrode was $-7.96 \pm 0.16 \mathrm{~mA}$. Maximum current values of SSW and SSM using the stainless steel wire and mesh as the counter electrodes were $-7.15 \pm 0.19$ and $-6.53 \pm 0.23 \mathrm{~mA}$, respectively. $\mathrm{CV}$ of maximum currents was the lowest in BB (1.76\%), followed by PtW $(2.01 \%), \operatorname{SSW}(2.72 \%), \mathrm{AB}(3.43 \%)$ and SSM (3.44\%) (Figure 4). BB had 12.4\% lower CV than PtW. In addition, it showed $48.6 \%$ lower $\mathrm{CV}$ than $\mathrm{AB}$ without biofilm. When with acetate filled, cathode LSV test using a biological brush as counter electrode showed that maximum current and reproducibility were high.

In order to compare the more accurate reproducibility from each counter electrode, the cathode LSV test method was performed without acetate filled [7]. Maximum current value of BB and AB was $-8.87 \pm 0.15$ and $-6.19 \pm 0.17 \mathrm{~mA}$. Maximum current of PtW was $-6.07 \pm 0.07 \mathrm{~mA}$. Maximum current of $\mathrm{BB}$ was higher than other counter electrodes as in the previous cathode LSV test with acetate filled. However, CV of maximum currents was the lowest in PtW (1.24\%), followed by BB (1.71\%), AB $(2.73 \%)$, SSM (3.64\%) and SSW (4.17\%) (Figure 4). PtW had 27.4\% lower CV than BB. When without acetate filled, the reproducibility was high in using $\mathrm{Pt}$ wire as counter electrode.

\section{(Figure 3, Figure 4)}

\subsection{Ni-AC-SSM cathode linear sweep voltammetry test}

Cathode LSV test reproducibility was evaluated using Ni-AC-SSM cathode with higher activity for hydrogen evolution reaction (HER) than stainless steel (Figure 5, S3). Maximum current values of $\mathrm{BB}$ and $\mathrm{AB}$ with acetate filled were $-16.01 \pm 1.41$ and $-16.99 \pm 3.73 \mathrm{~mA}$, respectively. Maximum current value of PtW was $-13.26 \pm 0.47 \mathrm{~mA}$. Maximum current values of SSW and SSM were $-13.96 \pm 1.27$ and $-13.59 \pm 2.02 \mathrm{~mA}$, respectively (Table 1). Maximum current of $\mathrm{AB}$ was higher than other counter electrodes. However, CV of maximum currents was the lowest in PtW (3.54\%), followed by BB (8.81\%), SSW (9.13\%), SSM (14.82\%) and AB (21.95\%) (Figure 6).

Maximum current values of $\mathrm{BB}$ and $\mathrm{AB}$ without acetate filled were $-15.73 \pm 1.15$ and $-12.44 \pm 0.30$ $\mathrm{mA}$, respectively. Maximum current value of $\mathrm{PtW}$ was $-13.11 \pm 0.08 \mathrm{~mA}$. Maximum current values of SSW and SSM were $-11.95 \pm 0.15$ and $-13.57 \pm 0.70 \mathrm{~mA}$, respectively. Maximum current of BB was higher than other counter electrodes. However, CV of maximum currents was the lowest in PtW 
(0.61\%), followed by SSW (1.21\%), AB (2.43\%), SSM (5.15\%) and BB (7.31\%) (Figure 6). In Ni-AC-SSM cathode LSV test, reproducibility using Pt wire as counter electrode regardless of the substrate was the best.

\section{(Figure 5, Figure 6, Table 1)}

\section{Discussion}

\subsection{Reproducibility of anode linear sweep voltammetry test}

The reproducibility of biological brush anode LSV tests was evaluated by changing the counter electrode. Maximum current of SSM was $13.9 \%$ and $13.3 \%$ higher than PtW and SSW because the stainless steel mesh had the largest surface area among the three counter electrodes [30,31].

Anode LSV tests showed excellent reproducibility when stainless steel (SS) was used than Pt as counter electrode (Figure 2). CV of maximum currents was 79.2\% and 77.8\% lower for SSW and SSM than PtW, respectively. In the operation of MEC, cathode was used as stainless steel mesh. Therefore, it can be demonstrated that the reproducibility of anode LSV test is high when the same counter electrode as the operating condition is used.

\subsection{Reproducibility of cathode linear sweep voltammetry test}

Unlike an anode LSV test, cathode LSV test is almost conducted without a substrate [23,24,28,32]. However, in this study, cathode LSV tests were conducted to compare the reproducibility when using various counter electrodes, including biological and abiotic electrode. Therefore, the comparison was conducted according to with and without acetate filled as a substrate.

In cathode LSV test with acetate filled, BB had the highest maximum current value, because the biofilm of carbon brush used as counter electrode had high electrochemical activity (Table 1). This result can be demonstrated from previous studies [33-35] that have improved the electrochemical performance of MEC by using bio-cathodes as counter electrodes.

The reproducibility of SSM cathode LSV test was high in BB. CV of BB was lower $12.4 \%, 48.7 \%$ than PtW and SSM, it was also lower by $48.6 \%$ than AB without biofilm. This result showed enhanced reproducibility by electrochemically active biofilm. In addition, like the anode LSV test, showed high reproducibility in the counter electrode (biological brush anode) was used during MEC operation.

However, the substrate had an effect on the electro-activity of the counter electrode, so the reproducibility of SSM cathode LSV test was evaluated without acetate filled. Maximum current was high in BB, but CV were the lowest in PtW, followed by BB (Figure 4). The results showed that under LSV test conditions without acetate filled, the use of Pt wire as counter electrode was excellent in reproducibility.

In order to compare tendency of results, Ni-AC-SSM cathode fabricated by a blended of AC and Ni Powder were also tested. There was a difference in cathode performance, maximum current value of Ni-AC-SSM cathode was generally higher than SSM cathode because of the high activity about HER. Ni-AC-SSM cathode has a larger surface area than SSM and higher electrical conductivity due to mixed ACs [8], but it is low durability and reproducibility because of the attached cathode catalysts to current collector [36]. Therefore, in the cathode LSV tests, Ni-AC-SSM cathode had higher CVs than SSM, reproducibility was overall not good (Table 1).

$\mathrm{CV}$ value was low in without acetate filled than with acetate filled (Figure 6). This result demonstrates that reproducibility without acetate filled is better when conducting LSV tests of cathode. The CV of LSV test with acetate filled was lowest in PtW, followed by BB. However, The CV of LSV test without acetate filled was exclusively lowest in PtW. Based on the results of all experiments, it was proved that the reproducibility is high when the electrode LSV test is performed under the same conditions (counter electrode, substrate) as the MEC operation. However, it is 
recommended to use the Pt electrode as a counter electrode and without a substrate for the cathode LSV test. It indicates that it is more important that counter electrode is not electrochemically polarized during LSV test without acetate filled.

\section{Conclusions}

In this study, anode and cathode LSV tests were conducted using various counter electrodes to evaluate the reproducibility. Counter electrodes to be used in electrodes LSV tests that perform different reactions, such as anode and cathode, could be different.

The consideration when selecting a counter electrode in the anode LSV test is the material of the cathode used during MEC operation. In this study, cathode of MEC was used as stainless steel mesh. Therefore, reproducibility of anode LSV test was high in using stainless steel than Pt as counter electrode.

The factors to consider when selecting a counter electrode in the cathode LSV test is a substrate. The counter electrode in the cathode LSV test with and without acetate filled was evaluated. Reproducibility of cathode LSV test with acetate filled was high when the biological brush, which was the anode during the MEC operation, was used as the counter electrode. This is considered to be due to the biofilm electrochemical activity of biological brush and using the adapted anode as counter electrode in MEC operation mode.

However, reproducibility was high when using Pt wire as counter electrode in the cathode LSV test without acetate filled. This is because $\mathrm{Pt}$ is not electrochemically polarized as a counter electrode in the cathode LSV test without acetate filled. Therefore, the method for LSV test with high reproducibility is: 1) to use the same counter electrode as the MEC operating conditions (with substrate filled), and 2) use Pt electrode when the substrate is not filled. These data results suggest that counter electrodes can be set according to the various conditions in anode and cathode LSV test.

Supplementary Materials: Figure S1: LSV curves (second set) of a biological brush anode. Platinum wire (PtW), stainless steel wire (SSW) or stainless steel mesh (SSM) is used as a counter electrode. $100 \mathrm{mM}$ CBS with $20 \mathrm{mM}$ acetate was used as a medium, Figure S2: LSV curves (second set) of a stainless steel mesh (SSM) cathode. Biological brush (BB), abiotic carbon brush (AB), platinum wire (PtW), stainless steel wire (SSW) or stainless steel mesh (SSM) was used as a counter electrode. LSV was performed in $20 \mathrm{mM}$ acetate (A and C) and nonacetate (B and D) in $100 \mathrm{mM}$ CBS, Figure S3: LSV curves (second set) of Ni-AC-SSM cathode. Biological brush (BB), abiotic carbon brush (AB), platinum wire (PtW), stainless steel wire (SSW) or stainless steel mesh (SSM) was used as a counter electrode. LSV was performed in $20 \mathrm{mM}$ acetate (A and C) and non-acetate (B and D) in $100 \mathrm{mM}$ CBS.

Author Contributions: Conceptualization, H. Chai and S. P. Jung; methodology, H. Chai and S. P. Jung; validation, S. P. Jung; investigation, B. Koo and S. Son; writing-original draft preparation, H. Chai and S. P. Jung; writing-review and editing, B. Koo, S. Son and S. P. Jung; supervision, S. P. Jung; All authors have read and agreed to the published version of the manuscript.

Funding: This research was supported by Basic Science Research Program through the National Research Foundation of Korea (NRF) funded by the Ministry of Education (NRF-2018R1D1A1B07050567), a research grant from Gwangju Green Environment Center in Ministry of Environment (19-04-70-79-12).

Conflicts of Interest: The authors declare no conflict of interest. 


\section{References}

1. Duce, R.A.; LaRoche, J.; Altieri, K.; Arrigo, K.R.; Baker, A.R.; Capone, D.; Cornell, S.; Dentener, F.; Galloway, J.; Ganeshram, R.S. Impacts of atmospheric anthropogenic nitrogen on the open ocean. science 2008, 320, 893-897.

2. Logan, B.E.; Rabaey, K. Conversion of wastes into bioelectricity and chemicals by using microbial electrochemical technologies. Science 2012, 337, 686-690.

3. Logan, B.E.; Call, D.; Cheng, S.; Hamelers, H.V.; Sleutels, T.H.; Jeremiasse, A.W.; Rozendal, R.A. Microbial electrolysis cells for high yield hydrogen gas production from organic matter. Environ. Sci. Technol. 2008, 42, 8630-8640.

4. Wang, H.; Ren, Z.J. A comprehensive review of microbial electrochemical systems as a platform technology. Biotechnol. Adv. 2013, 31, 1796-1807.

5. Kumar, G.; Bakonyi, P.; Zhen, G.; Sivagurunathan, P.; Koók, L.; Kim, S.-H.; Tóth, G.; Nemestóthy, N.; Bélafi-Bakó, K. Microbial electrochemical systems for sustainable biohydrogen production: surveying the experiences from a start-up viewpoint. Renewable and Sustainable Energy Reviews 2017, 70, 589-597.

6. Liu, H.; Logan, B.E. Electricity generation using an air-cathode single chamber microbial fuel cell in the presence and absence of a proton exchange membrane. Environmental science E technology 2004, 38, 40404046 .

7. Lu, L.; Hou, D.; Fang, Y.; Huang, Y.; Ren, Z.J. Nickel based catalysts for highly efficient H2 evolution from wastewater in microbial electrolysis cells. Electrochimica Acta 2016, 206, 381-387.

8. Kim, K.-Y.; Logan, B.E. Nickel powder blended activated carbon cathodes for hydrogen production in microbial electrolysis cells. International Journal of Hydrogen Energy 2019, 44, 13169-13174.

9. Santoro, C.; Serov, A.; Gokhale, R.; Rojas-Carbonell, S.; Stariha, L.; Gordon, J.; Artyushkova, K.; Atanassov, P. A family of Fe-NC oxygen reduction electrocatalysts for microbial fuel cell (MFC) application: relationships between surface chemistry and performances. Applied Catalysis B: Environmental 2017, 205, 24-33.

10. Kang, H.; Jeong, J.; Gupta, P.L.; Jung, S.P. Effects of brush-anode configurations on performance and electrochemistry of microbial fuel cells. international journal of hydrogen energy 2017, 42, 27693-27700.

11. Nam, T.; Son, S.; Koo, B.; Tran, H.V.H.; Kim, J.R.; Choi, Y.; Jung, S.P. Comparative evaluation of performance and electrochemistry of microbial fuel cells with different anode structures and materials. International Journal of hydrogen energy 2017, 42, 27677-27684.

12. Jung, S.P.; Kim, E.; Koo, B. Effects of wire-type and mesh-type anode current collectors on performance and electrochemistry of microbial fuel cells. Chemosphere 2018, 209, 542-550.

13. Koo, B.; Lee, S.-M.; Oh, S.-E.; Kim, E.J.; Hwang, Y.; Seo, D.; Kim, J.Y.; Kahng, Y.H.; Lee, Y.W.; Chung, S.-Y. Addition of reduced graphene oxide to an activated-carbon cathode increases electrical power generation of a microbial fuel cell by enhancing cathodic performance. Electrochimica Acta 2019, 297, 613-622.

14. Jung, S.; Mench, M.M.; Regan, J.M. Impedance characteristics and polarization behavior of a microbial fuel cell in response to short-term changes in medium pH. Environmental science $\mathcal{E}$ technology 2011, 45, 9069-9074.

15. Kenjo, T.; Yamakoshi, Y.; Wada, K. An Estimation of the Electrode-Electrolyte Contact Area by Linear Sweep Voltammetry in Pt/ZrO2 Oxygen Electrodes. Journal of The Electrochemical Society 1993, 140, 2151. 
16. Zago, M.; Baricci, A.; Bisello, A.; Jahnke, T.; Yu, H.; Maric, R.; Zelenay, P.; Casalegno, A. Experimental analysis of recoverable performance loss induced by platinum oxide formation at the polymer electrolyte membrane fuel cell cathode. Journal of Power Sources 2020, 455, 227990.

17. Gao, S.; Wang, B.; Liu, Z. Enhanced hydrogen production of PbTe-PbS/TNAs electrodes modified with ordered mesoporous carbon. Journal of colloid and interface science 2017, 504, 652-659.

18. Han, G.-Q.; Shang, X.; Lu, S.-S.; Dong, B.; Li, X.; Liu, Y.-R.; Hu, W.-H.; Zeng, J.-B.; Chai, Y.-M.; Liu, C.G. Electrodeposited MoSx films assisted by liquid crystal template with ultrahigh electrocatalytic activity for hydrogen evolution reaction. Int. J. Hydrogen Energy 2017, 42, 5132-5138.

19. Skoog, D.A.; Holler, F.J.; Crouch, S.R. Principles of instrumental analysis; Cengage learning: 2017.

20. Bard, A. Electrochemical Merhods. Fundamentals and applications 1980, 290.

21. Jafary, T.; Daud, W.R.W.; Ghasemi, M.; Bakar, M.H.A.; Sedighi, M.; Kim, B.H.; Carmona-Martínez, A.A.; Jahim, J.M.; Ismail, M. Clean hydrogen production in a full biological microbial electrolysis cell. International Journal of Hydrogen Energy 2019, 44, 30524-30531.

22. Huang, Y.-X.; Liu, X.-W.; Sun, X.-F.; Sheng, G.-P.; Zhang, Y.-Y.; Yan, G.-M.; Wang, S.-G.; Xu, A.-W.; Yu, H.-Q. A new cathodic electrode deposit with palladium nanoparticles for cost-effective hydrogen production in a microbial electrolysis cell. international journal of hydrogen energy 2011, 36, 2773-2776.

23. Li, F.; Liu, W.; Sun, Y.; Ding, W.; Cheng, S. Enhancing hydrogen production with Ni-P coated nickel foam as cathode catalyst in single chamber microbial electrolysis cells. International Journal of Hydrogen Energy 2017, 42, 3641-3646.

24. Wang, L.; Chen, Y.; Huang, Q.; Feng, Y.; Zhu, S.; Shen, S. Hydrogen production with carbon nanotubes based cathode catalysts in microbial electrolysis cells. Journal of Chemical Technology E Biotechnology 2012, $87,1150-1156$.

25. Pasupuleti, S.B.; Srikanth, S.; Mohan, S.V.; Pant, D. Development of exoelectrogenic bioanode and study on feasibility of hydrogen production using abiotic VITO-CoRE ${ }^{\mathrm{TM}}$ and VITO-CASE ${ }^{\mathrm{TM}}$ electrodes in a single chamber microbial electrolysis cell (MEC) at low current densities. Bioresource technology 2015, 195, 131-138.

26. Roubaud, E.; Lacroix, R.; Da Silva, S.; Bergel, A.; Basséguy, R.; Erable, B. Catalysis of the hydrogen evolution reaction by hydrogen carbonate to decrease the voltage of microbial electrolysis cell fed with domestic wastewater. Electrochimica Acta 2018, 275, 32-39.

27. Lamp, J.L.; Guest, J.S.; Naha, S.; Radavich, K.A.; Love, N.G.; Ellis, M.W.; Puri, I.K. Flame synthesis of carbon nanostructures on stainless steel anodes for use in microbial fuel cells. Journal of Power Sources 2011, 196, 5829-5834.

28. Selembo, P.A.; Merrill, M.D.; Logan, B.E. Hydrogen production with nickel powder cathode catalysts in microbial electrolysis cells. Int. J. Hydrogen Energy 2010, 35, 428-437.

29. Feng, Y.; Yang, Q.; Wang, X.; Logan, B.E. Treatment of carbon fiber brush anodes for improving power generation in air-cathode microbial fuel cells. Journal of Power Sources 2010, 195, 1841-1844.

30. Zhang, Y.; Merrill, M.D.; Logan, B.E. The use and optimization of stainless steel mesh cathodes in microbial electrolysis cells. international journal of hydrogen energy 2010, 35, 12020-12028.

31. Call, D.F.; Merrill, M.D.; Logan, B.E. High surface area stainless steel brushes as cathodes in microbial electrolysis cells. Environmental science \& technology 2009, 43, 2179-2183.

32. Cai, W.; Liu, W.; Han, J.; Wang, A. Enhanced hydrogen production in microbial electrolysis cell with 3D self-assembly nickel foam-graphene cathode. Biosensors and Bioelectronics 2016, 80, 118-122. 
33. Kim, B.H.; Lim, S.S.; Daud, W.R.W.; Gadd, G.M.; Chang, I.S. The biocathode of microbial electrochemical systems and microbially-influenced corrosion. Bioresource technology 2015, 190, 395-401.

34. Rozendal, R.A.; Jeremiasse, A.W.; Hamelers, H.V.; Buisman, C.J. Hydrogen production with a microbial biocathode. Environ. Sci. Technol. 2008, 42, 629-634.

35. Lim, S.S.; Kim, B.H.; Li, D.; Feng, Y.; Daud, W.R.W.; Scott, K.; Yu, E.H. Effects of applied potential and reactants to hydrogen-producing biocathode in a microbial electrolysis cell. Frontiers in chemistry 2018, 6,318 .

36. Zhou, W.; Jia, J.; Lu, J.; Yang, L.; Hou, D.; Li, G.; Chen, S. Recent developments of carbon-based electrocatalysts for hydrogen evolution reaction. Nano Energy 2016, 28, 29-43. 


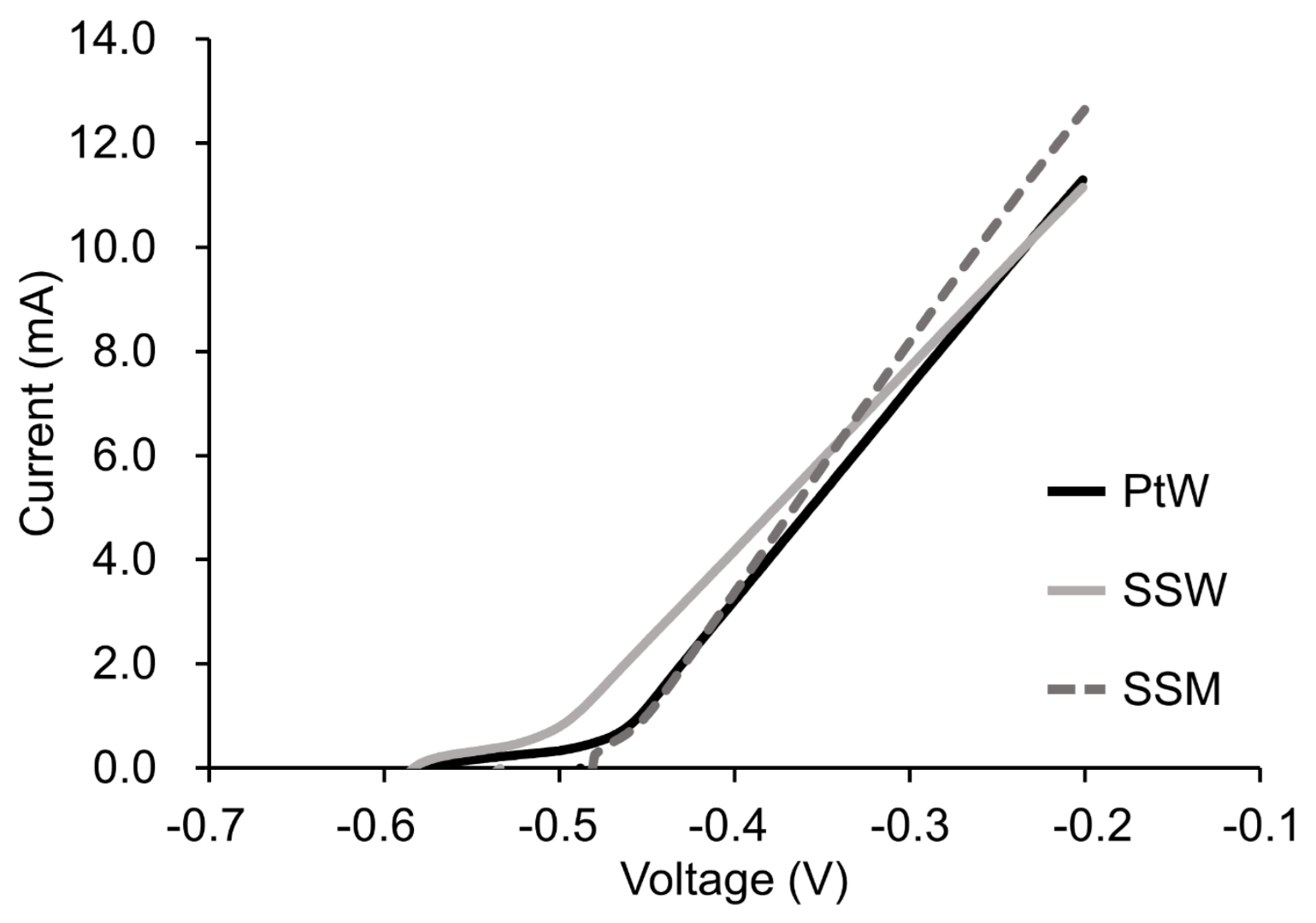

Figure 1. Anode LSV curves of a biological brush anode (first set). Platinum wire (PtW), stainless steel wire (SSW) or stainless steel mesh (SSM) is used as a counter electrode. $100 \mathrm{mM}$ CBS medium with 20 $\mathrm{mM}$ acetate was used as a medium. 


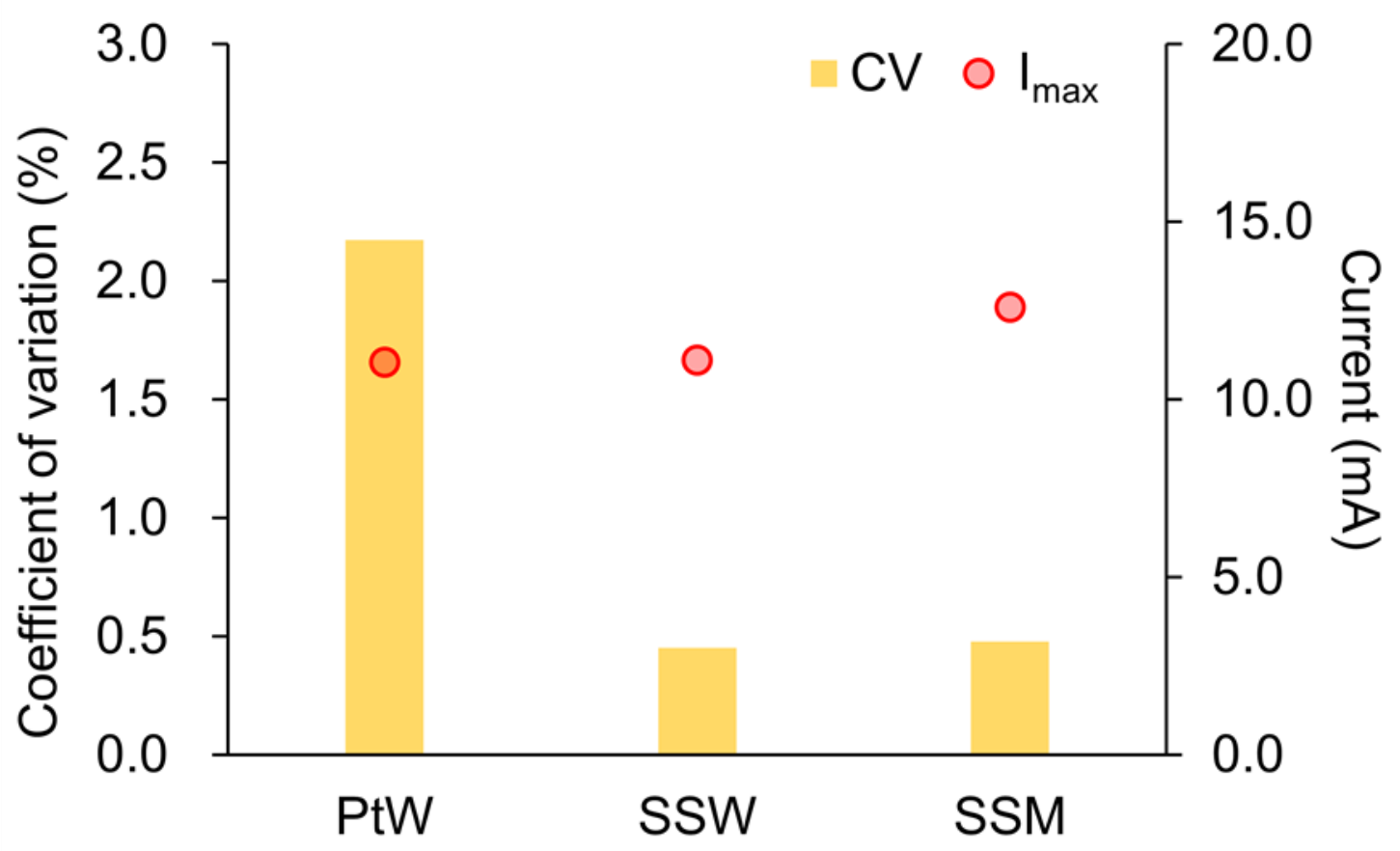

Figure 2. Coefficient of variation and maximum current in BB anode LSV in the acetate-added CBS medium. 

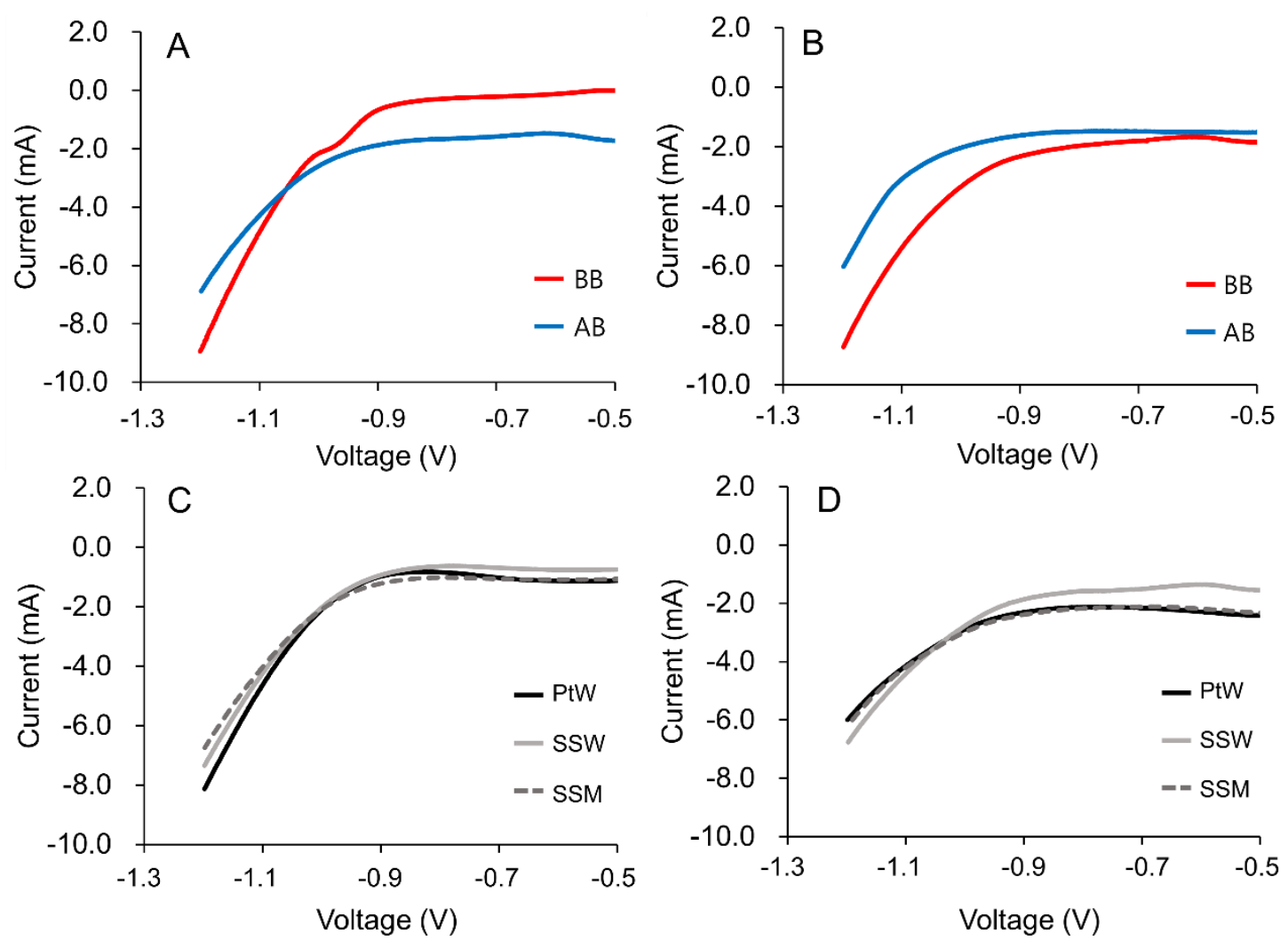

Figure 3. Cathodic LSV curves of stainless steel mesh (SSM) cathode (first set). Biological brush (BB), abiotic carbon brush $(\mathrm{AB})$, platinum wire $(\mathrm{PtW})$, stainless steel wire (SSW) or stainless steel mesh (SSM) was used as a counter electrode. LSV was performed in the acetate condition (20 $\mathrm{mM})(\mathrm{A}$ and C) or the non-acetate condition (B and D) in the $100 \mathrm{mM}$ CBS medium. 


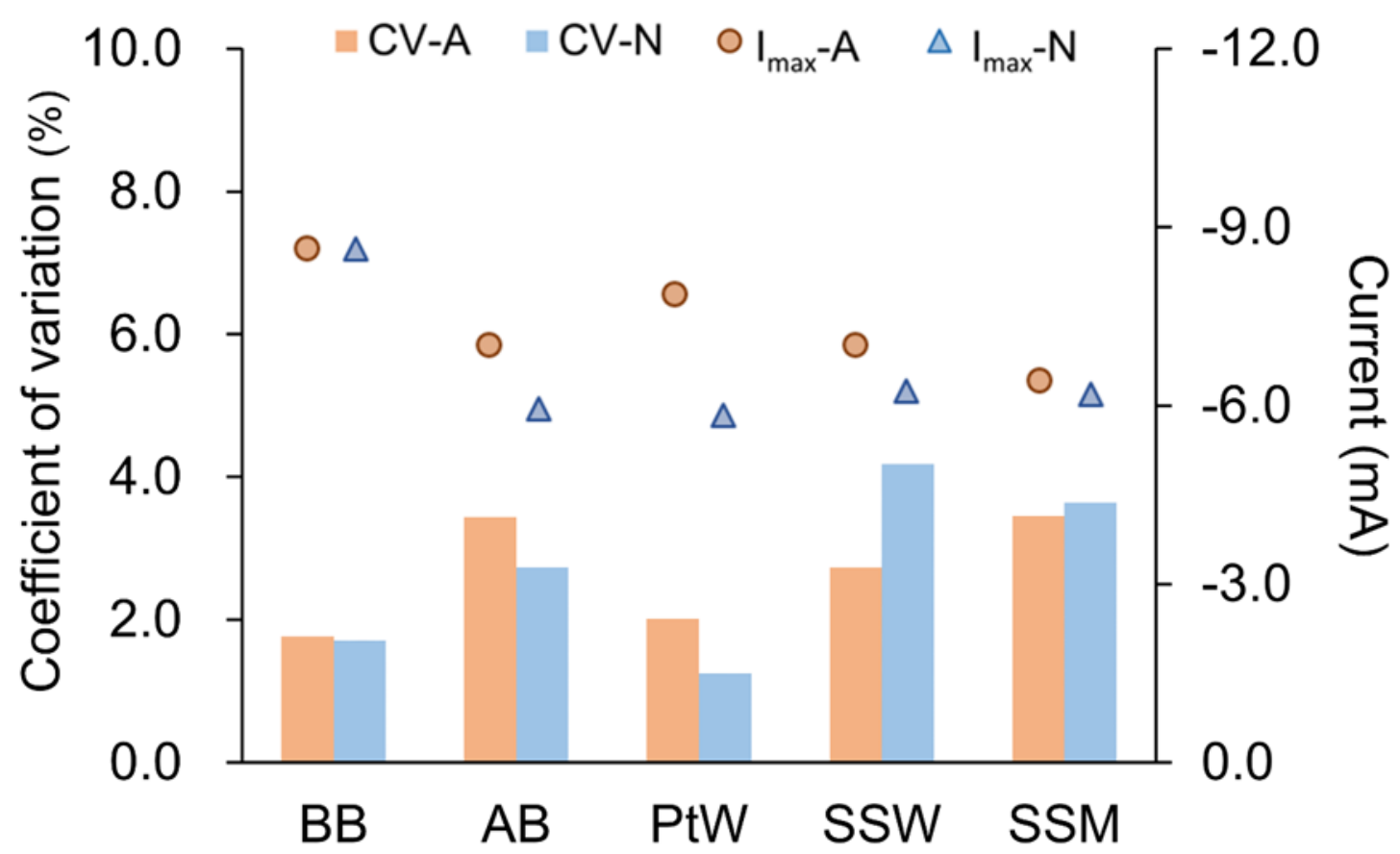

Figure 4. Coefficient of variation (CV) and maximum current (Imax) from the LSV curves of the SSM cathode. CV-A: CV in the acetate condition, CV-N: CV in the non-acetate condition, Imax-A: Imax in the acetate condition, $I_{\max }-\mathrm{N}$ : $I_{\max }$ in the non-acetate condition. 

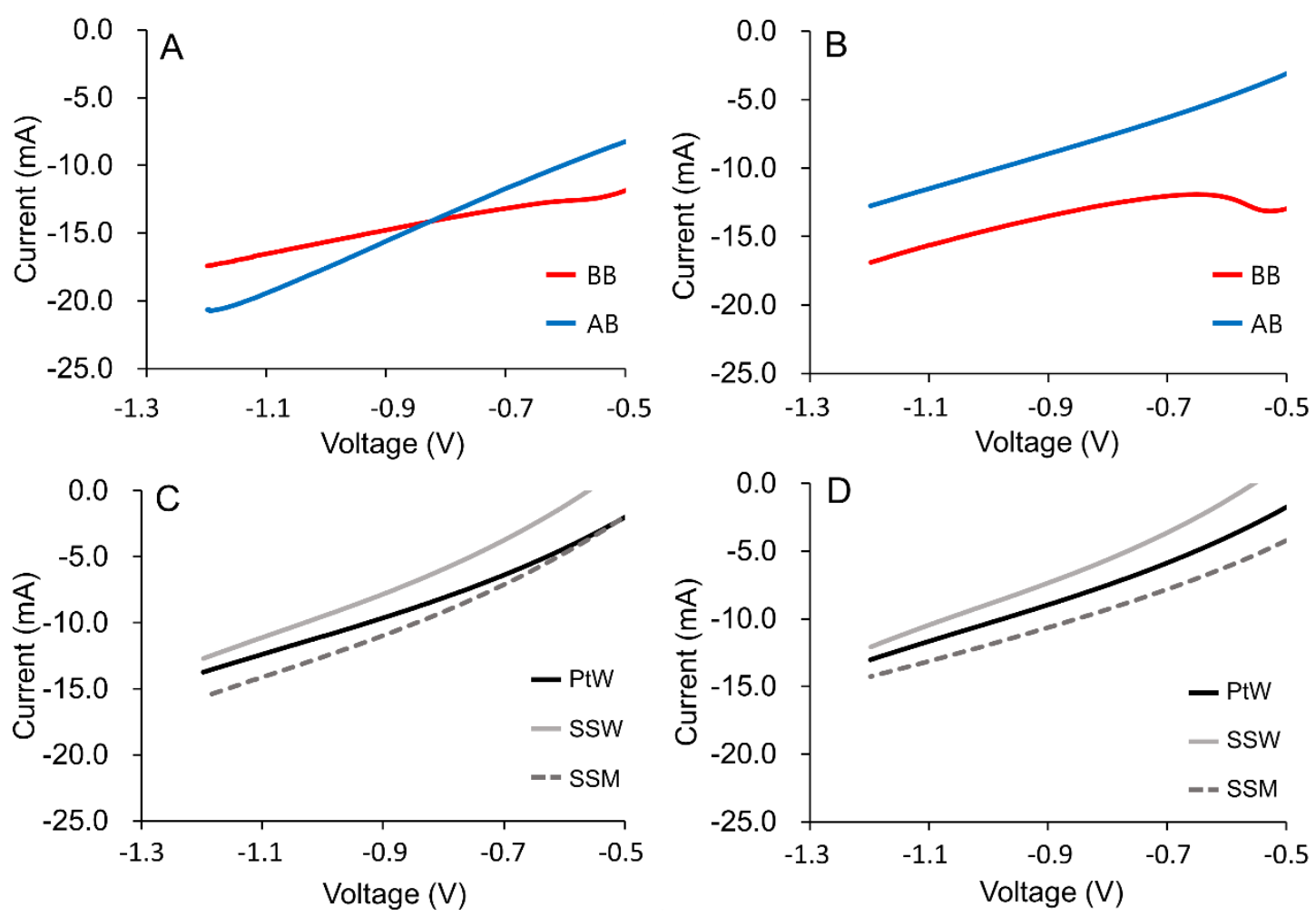

Figure 5. Cathodic LSV curves of Ni-AC-SSM cathode (first set). Biological brush (BB), abiotic carbon brush (AB), platinum wire (PtW), stainless steel wire (SSW) or stainless steel mesh (SSM) was used as a counter electrode. LSV was performed in the acetate condition $(20 \mathrm{mM})(\mathrm{A}$ and $\mathrm{C})$ or the non-acetate condition (B and D) in 100 mM CBS medium. 


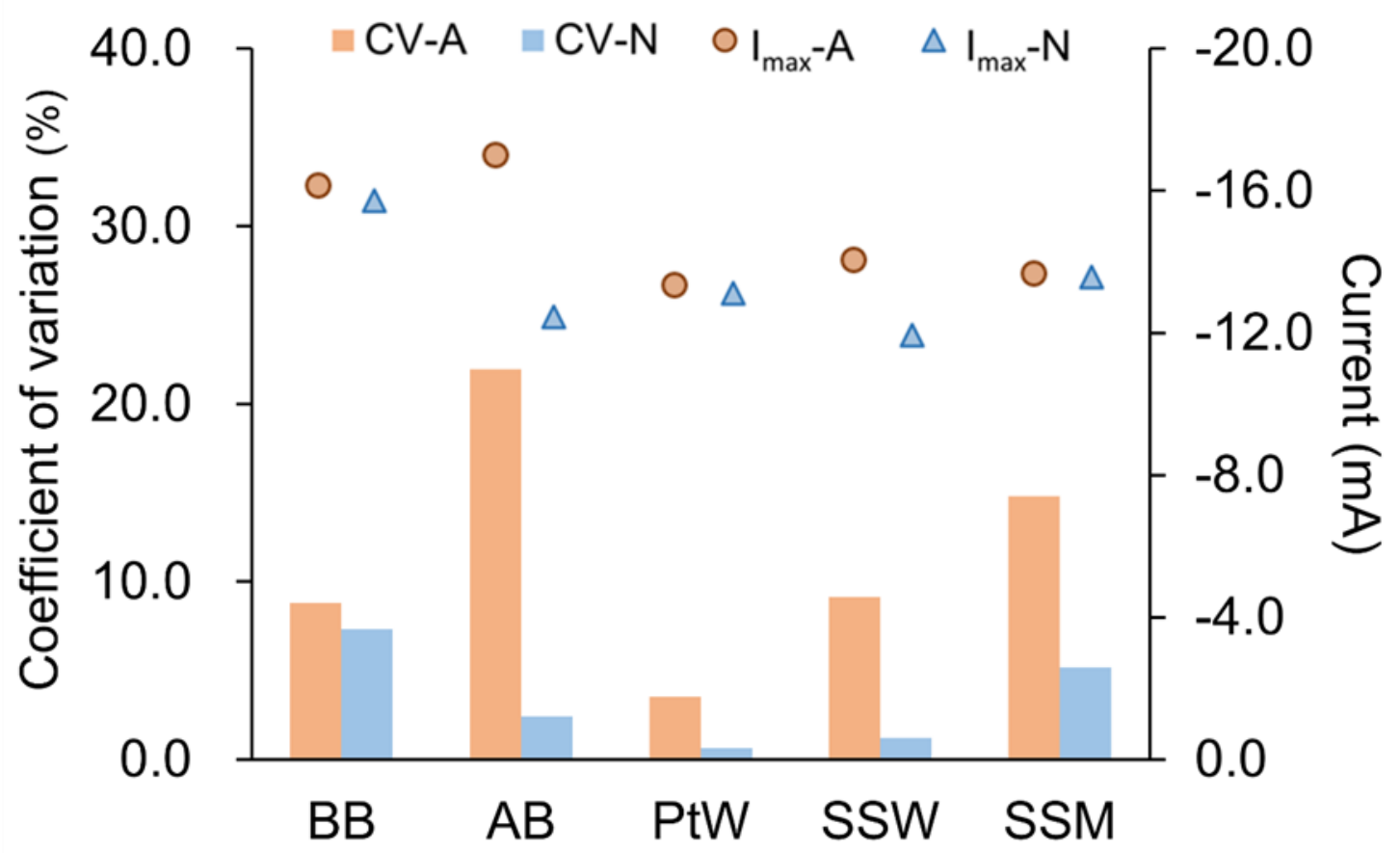

Figure 6. Coefficient of variation $(\mathrm{CV})$ and maximum current $\left(I_{\max }\right)$ from the LSV curves of the Ni-ACSSM cathode. CV-A: CV in the acetate condition, CV-N: CV in the non-acetate condition, Imax-A: Imax in the acetate condition, $I_{\max }-\mathrm{N}$ : Imax in the non-acetate condition. 
Table 1. Coefficients of variation (CV) and maximum current (Imax) in LSV tests. ( $n=2)$. LSV was performed in the acetate condition $(20 \mathrm{mM})$ or the non-acetate condition in the $100 \mathrm{mM}$ CBS medium: biological brush (BB), abiotic carbon brush (AB), platinum wire (PtW), stainless steel wire (SSW), stainless steel mesh (SSM), activated carbon cathode with nickel powder (Ni-AC-SSM)

\begin{tabular}{|c|c|c|}
\hline \multicolumn{3}{|c|}{ BB anode (acetate) } \\
\hline $\begin{array}{l}\text { Counter } \\
\text { electrode }\end{array}$ & $\mathrm{CV}(\%)$ & $\operatorname{Imax}(m A)$ \\
\hline PtW & 2.17 & $11.05 \pm 0.24$ \\
\hline SSW & 0.45 & $11.11 \pm 0.05$ \\
\hline SSM & 0.48 & $12.59 \pm 0.06$ \\
\hline \multicolumn{3}{|c|}{ SSM cathode (acetate) } \\
\hline $\begin{array}{l}\text { Counter } \\
\text { electrode }\end{array}$ & CV $(\%)$ & $\operatorname{Imax}(m A)$ \\
\hline $\mathrm{BB}$ & 1.76 & $-8.79 \pm 0.15$ \\
\hline $\mathrm{AB}$ & 3.43 & $-7.12 \pm 0.25$ \\
\hline $\mathrm{PtW}$ & 2.01 & $-7.96 \pm 0.16$ \\
\hline SSW & 2.72 & $-7.15 \pm 0.19$ \\
\hline SSM & 3.44 & $-6.53 \pm 0.23$ \\
\hline \multicolumn{3}{|c|}{ SSM cathode (non-acetate) } \\
\hline $\begin{array}{l}\text { Counter } \\
\text { electrode }\end{array}$ & $\mathrm{CV}(\%)$ & $\operatorname{Imax}(m A)$ \\
\hline $\mathrm{BB}$ & 1.71 & $-8.87 \pm 0.15$ \\
\hline $\mathrm{AB}$ & 2.73 & $-6.19 \pm 0.17$ \\
\hline $\mathrm{PtW}$ & 1.24 & $-6.07 \pm 0.07$ \\
\hline SSW & 4.17 & $-6.49 \pm 0.27$ \\
\hline SSM & 3.64 & $-6.44 \pm 0.23$ \\
\hline \multicolumn{3}{|c|}{ Ni-AC-SSM cathode (acetate) } \\
\hline $\begin{array}{l}\text { Counter } \\
\text { electrode }\end{array}$ & CV $(\%)$ & $\operatorname{Imax}(m A)$ \\
\hline $\mathrm{BB}$ & 8.81 & $-16.01 \pm 1.41$ \\
\hline $\mathrm{AB}$ & 21.95 & $-16.99 \pm 3.73$ \\
\hline $\mathrm{PtW}$ & 3.54 & $-13.26 \pm 0.47$ \\
\hline SSW & 9.13 & $-13.96 \pm 1.27$ \\
\hline SSM & 14.82 & $-13.59 \pm 2.02$ \\
\hline \multicolumn{3}{|c|}{ Ni-AC-SSM cathode (non-acetate) } \\
\hline $\begin{array}{l}\text { Counter } \\
\text { electrode }\end{array}$ & $\mathrm{CV}(\%)$ & $\operatorname{Imax}(m A)$ \\
\hline $\mathrm{BB}$ & 7.31 & $-15.73 \pm 1.15$ \\
\hline $\mathrm{AB}$ & 2.43 & $-12.44 \pm 0.30$ \\
\hline $\mathrm{PtW}$ & 0.61 & $-13.11 \pm 0.08$ \\
\hline SSW & 1.21 & $-11.95 \pm 0.15$ \\
\hline SSM & 5.15 & $-13.57 \pm 0.70$ \\
\hline
\end{tabular}

